\title{
CLINICAL OBSERVATIONS ON PYLORIC STENOSIS IN PREMATURE INFANTS
}

\author{
BY \\ J. L. HENDERSON, J. J. MASON BROWN and W. C. TAYLOR \\ From the Department of Child Life and Health, University of Edinburgh, and the Simpson Maternity. \\ Hospital, Edinburgh
}

(RECEIVED FOR PUBLICATION JULY 12, 1951)

Little attention has been given in the past to the incidence and clinical features of hypertrophic pyloric stenosis in premature infants. We have observed three cases of this disease in very premature infants within a period of 18 months in one of the premature nurseries in the Simpson Maternity Hospital, Edinburgh. These cases are of special interest because continuous clinical records from birth to convalescence are available. The literature contains a considerable number of brief references to pyloric stenosis in premature infants (Bloch, 1907; Steen, 1930; Donovan, 1932; Gallagher, 1937; Sheldon, 1938; Dobbs, 1939; Vickers and Conrad, 1940; Ford, Brown and McCreary, 1941; Levi, 1941; Williams, 1942; Todd, 1946: 1947; Laubscher and Smith, 1947; Josephs and Hendry, 1950), but no detailed clinical records such as these which illustrate the manner of development of the disease, and certain features which appear to be peculiar to premature infants.

The smallest premature infant whom we have observed to develop the disease weighed $3 \mathrm{lb} .3 \mathrm{oz}$. at birth; this infant will not be included in this paper, because the clinical record is less detailed than in the cases of those recorded.

\section{Case Reconds}

Case 1. Male: a binovular twin.

Mother's last menstrual period, first day ... Expected date of delivery ...

Born .. $\quad . . \quad$.. $\quad . . \quad$ April 21, 1950

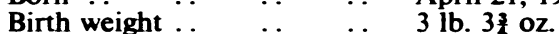

Foetal age at birth .. $\quad . .30$ weeks 3 days

Signs of pyloric stenosis began on the thirty-sixth day of life, that is at the foetal age of 35 weeks 4 days. Rammstedt's operation was performed at the foetal age of 36 weeks 4 days when the weight was $3 \mathrm{lb}$. $5 \frac{1}{2} \mathrm{oz}$.
The mother, who had mitral stenosis, developed pre-eclamptic toxaemia which necessitated the induction of labour during the thirty-first week of pregnancy. This was the second pregnancy: the first child was a girl. Male binovular twins were born spontaneously, the first being vertex L.O.A., and the second vertex R.O.A. The first, who weighed $3 \mathrm{lb}$. $3 t \mathrm{oz}$., later developed signs of pyloric stenosis, but the second, who weighed $3 \mathrm{lb}$. $5 \frac{1}{2} \mathrm{oz}$., died at the age of 39 hours. The latter baby showed clinical signs of the effects of intrapartum anoxia, notably atelectasis: necropsy confirmed intrapartum anoxia with subsequent respiratory failure as the cause of death; examination of the stomach did not show any evidence of pyloric stenosis.

The progress of the surviving twin during the first eight weeks of life, covering the period of illness caused by the pyloric stenosis and the early stages of convalescence after Rammstedt's operation, is shown in Fig. 1.

A'trufood' formula fortified with 'prosol' (62\% protein) compound was begun on the third day. Feeding was by gavage. The baby's condition steadily improved and the weight, after declining to $3 \mathrm{lb}$. $1 \mathrm{oz}$. on the tenth day, rose steadily and equalled the birth weight on the thirteenth day. During the fourth week the weight slowly declined but the temperature, which hitherto had usually been very subnormal, began to attain a higher level, though it remained unstable. At the end of the fourth week the baby vomited once on each of three successive days, but there was no further vomiting during the fifth week during which the weight increased steadily with a gain of $7 \frac{1}{2} \mathrm{oz}$. Vomiting recurred at the beginning of the sixth week, on the thirty-sixth day, when one vomit occurred. On the next two days there were three and six vomits respectively, several being copious. The steady weight gain of the fifth week was continued up to the thirtyeighth day, the third day of vomiting. Persistent vomiting continued through the following four days, accompanied by a subnormal number of stools and a rapid loss of weight amounting to $9 \frac{1}{2} \mathrm{oz}$. On the first of these days coffee-ground vomitus was seen on two occasions: on the second, which was the fortieth day of life, excessive gastric peristalsis was seen, a small 


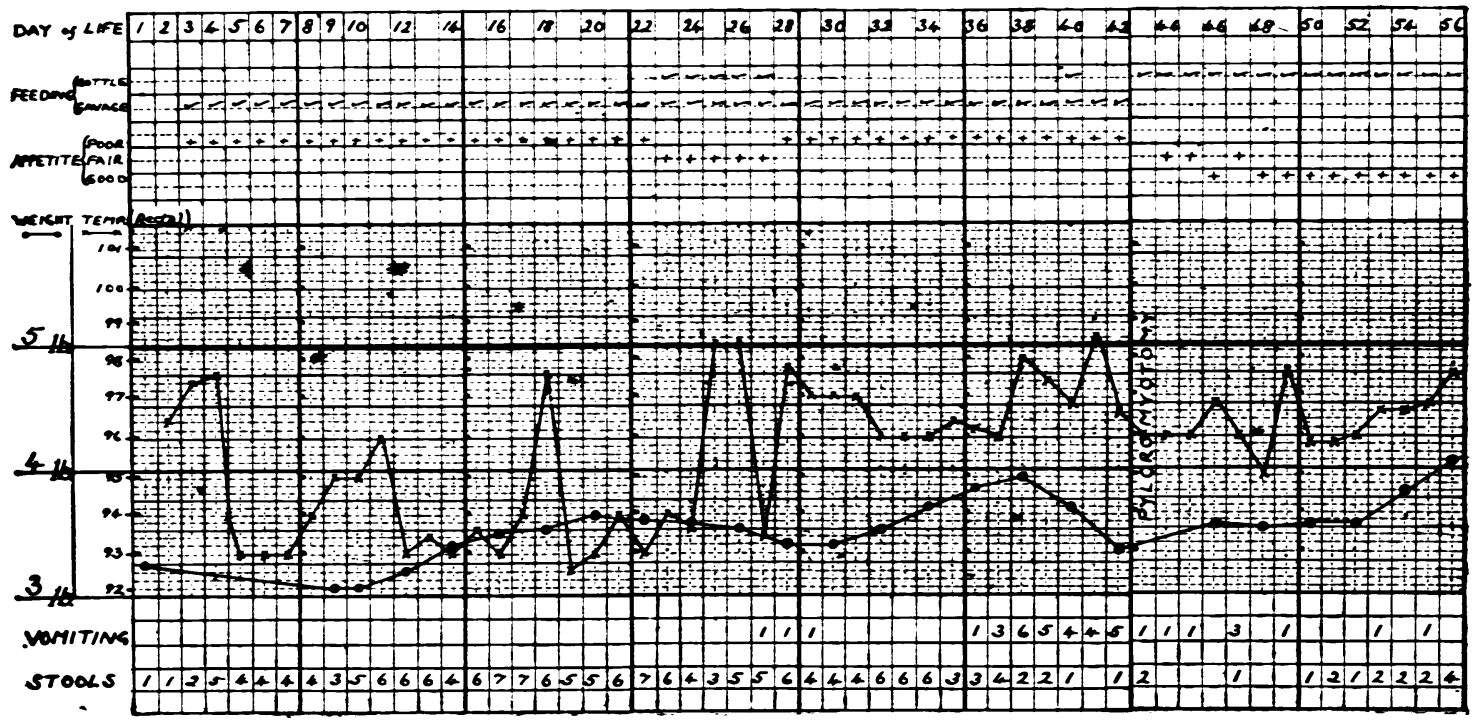

Fig. 1.-Clinical chart of Case 1 from birth until after recovery from pyloric stenosis.

pyloric tumour was felt and a diagnosis of pyloric stenosis made: and on the third projectile vomiting was first noted. On and after the third day of persistent vomiting fewer stools were passed. Occasional bottle feeds were given during most of the fourth week, but the appetite was so poor that bottle feeding was discontinued. It was again attempted on the day on which pyloric stenosis was diagnosed. but lack of appetite necessitated the resumption of gavage feeding which was continued up to the time of the operation on the forty-third day. The original 'trufood-prosol ${ }^{\cdot}$ formula was discontinued five days before the operation, and, after two days on glucose water, a regime of dilute sweetened condensed milk (Nestlè's) was instituted and continued up to the day of operation. During the three days between the diagnosis being made and the operation gastric lavage was carried out before some of the gavage feeds and saline hypodermoclyses with hyaluronidase were given to improve the baby"s hydration and general condition.

Rammstedt's operation was performed by J.J.M.B. on the forty-third day of life. The weight was then $3 \mathrm{lb}$. $5 \frac{1}{2} \mathrm{oz}$. Cyclopropane and local anaesthesia were used. A small, hard pyloric tumour was found. After the operation Nestle's milk was given in increasing strength and quantity for ten days when it was replaced by half-cream national dried milk. The appetite appeared to improve after the operation and all feeds were given by bottle: feeding was rather slow for the first three days but it was consistently good thereafter. A small vomit occurred once on each of the first three days of convalescence, and at less frequent intervals thereafter until a fortnight after the operation. Underfeeding accounted for the failure to gain weight and the infrequent stools until 10 days after the operation. A substantial increase of the diet at that stage was immediately followed by a rapid and steady gain in weight which continued until the infant was discharged from hospital at the age of $14 \frac{1}{2}$ weeks. when he weighed 7 lb. 2 oz.

Case 2. Male: single birth.

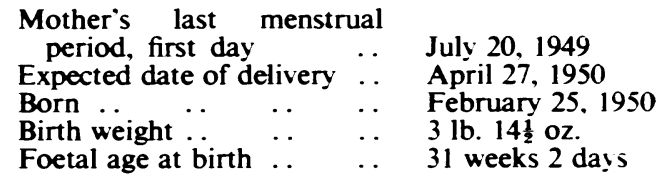

Signs of pyloric stenosis began on the tenth day of life, that is at the foetal age of 32 weeks 5 days. Rammstedt's operation was performed at the foetal age of 35 weeks 3 days when the weight was $3 \mathrm{lb} .2 \mathrm{oz}$.

The cause of the premature labour was not evident in this case. The birth was spontaneous, vertex L.O.A., and the infant 's condition was fairly good. He was the first child. Progress during the first six weeks of life. covering the period of illness caused by the pyloric stenosis and the early stages of convalescence after Rammstedt's operation, is shown in Fig. 2.

A 'trufood ' formula fortified with 'prosol ${ }^{\circ}\left(62^{\circ}\right.$ 。 protein) compound was begun on the second day. Progress was normal until the tenth day when the appetite deteriorated and feeding became slow. On the twelfth day the appetite improved, but the infant vomited twice. He continued to feed fairly well on the thirteenth day and there was no vomiting: the birth weight was regained on this day but no further weight gain occurred until after the operation. On the fourteenth day the appetite had become poor again and feeding slow, and vomiting occurred twice, the vomitus being copious on one occasion. On the fifteenth day feeding was slow 
throughout, but there was no vomiting. On the following day the feeding continued to be slow and two large vomits occurred. The weight, which had been stationary for two days, began to fall and continued to do so up to the day of operation: On the seventeenth day the anorexia continued and the infant vomited five times, the amount being large on three occasions. On the eighteenth day there was no change so the ${ }^{\cdot}$ trufoodprosol 'formula was replaced by $6 \%$ glucose solution. Anorexia and vomiting continued and some gavage feeding was instituted on the twentieth day, Nestle's milk, one part in seven parts of water, being substituted for the glucose solution. On the twenty-second day gavage feeding was discontinued because the appetite had improved, and diluted breast milk was substituted for Nestle's milk. Pyrexia, with a temperature of 101 F., was not explained. The improved appetite continued during the next day and no vomiting occurred for the first time for more than a week. The pyrexia, though diminished, continued. The improvement in feeding was short-lived, for on the following day, when whole breast milk was begun, the anorexia returned and there was one large vomit. Feeding was poor on the next day and there were seven vomits. During the next day feeding improved, the majority of the feeds being taken fairly well, but vomiting continued though less persistently. The unexplained pyrexia which had persisted for four days had subsided. On the following day, the twenty-eighth day of life, the slight improvement in feeding and diminution of vomiting were maintained. Exaggerated gastric peristalsis was observed, a pyloric tumour felt, and a diagnosis of pyloric stenosis made. The vomiting, which had been present for 16 days, was never described as projectile, though this characteristic may have occurred. The weight had fallen $12 \frac{1}{2} \mathrm{Oz}$. in the 13 days after it began to decline. The frequency of the stools had been subnormal for 12 days, there being none on two days.

On the twenty-ninth day of life, the day following the establishment of the diagnosis, a Rammstedt's operation was performed by J.J.M.B. The baby then weighed $3 \mathrm{lb} .2 \mathrm{oz}$. Cyclopropane and local anaesthesia were used. The pylorus was greatly enlarged. No further vomiting occurred after the operation, and the baby fed well from that time, on increasing amounts of glucose water on the day of operation, and on increasing amounts of breast milk thereafter. The weight rose $5 \mathrm{oz}$. in the first five days after the operation and $9 \mathrm{oz}$. in the following six days. The child continued to make good progress, and he weighed $6 \frac{1}{2} \mathrm{lb}$. when he was discharged from hospital at the age of 11 weeks. A right inguinal hernia was observed at the age of 10 weeks: this was operated on at the age of $6 \frac{1}{2}$ months. The infant then looked healthy.

Case 3. Male: single birth. Mother's last menstrual period, first day $\quad . . \quad$ May 15, 1948 Expected date of delivery .. $\quad$ February 22, 1949 Born .. $\quad$. . $\quad \ldots \quad$. . January 4, 1949 Birth weight $\ldots \quad \ldots \quad \ldots \quad 4 \mathrm{lb} .4 \mathrm{oz}$.

Foetal age at birth .. $\quad . .33$ weeks

Signs of pyloric stenosis began on the twenty-sixth day of life, that is at the foetal age of 36 weeks 5 days. Rammstedt's operation was performed at the foetal age of 38 weeks 4 days, when the weight was $3 \mathrm{lb}$. $11 \frac{1}{2} \mathrm{oz}$.

The mother was admitted to hospital with a revealed accidental haemorrhage and labour was induced surgically. The foetus was in the frank breech position and delivery was satisfactory, but the infant's condition was poor at birth. A very narrow head with a pronounced degree of dolichocephaly was observed. In the first $\mathbf{2 4}$ hours there were numerous transient attacks of respiratory failure with cyanosis, a common effect of the intrapartum anoxia so often produced in antepartum haemorrhage. This was the fifth child: the first four were all girls.

Progress during the first six weeks of life, covering the period of illness caused by the pyloric stenosis and the early stages of convalescence, is shown in Fig. 3.

Feeding was begun with diluted breast milk on the third day and continued with full breast milk on and after the fifth day. The appetite was poor in the early weeks, necessitating gavage feeding in the first week and partial gavage feeding in the second and third. The baby's condition steadily improved during the first week and had become fairly satisfactory by the end of it; the subnormal temperature persisted to the age of 2 weeks. The weight began to rise slowly on the tenth day, and

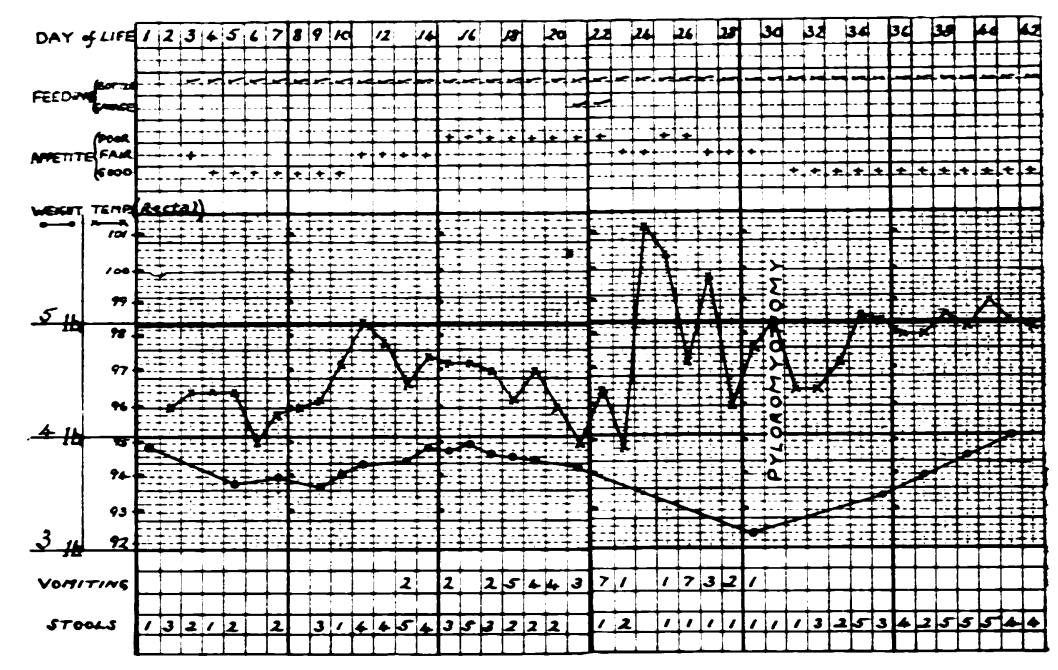

Fig. 2.-Clinical chart of Case 2 from birth until after recovery from pyloric stenosis. 


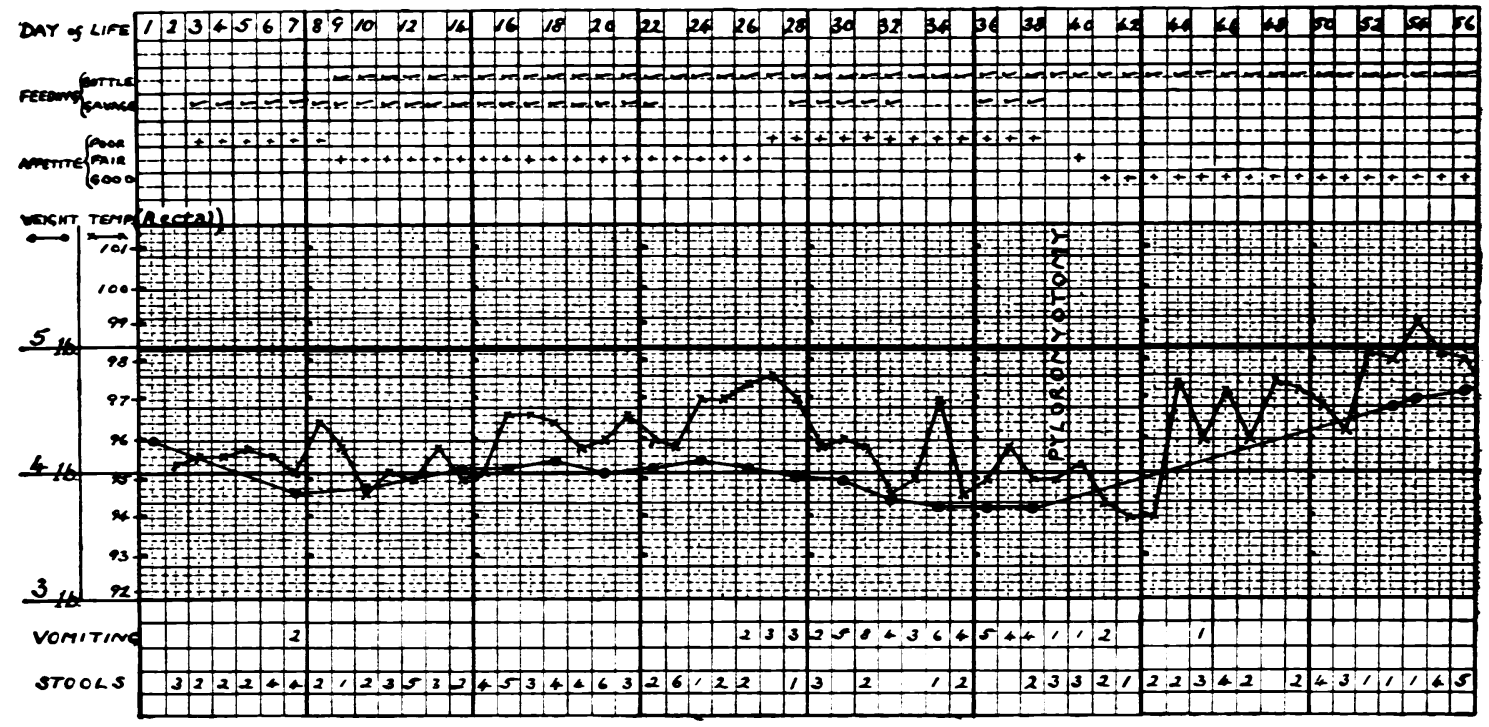

FIG. 3.-Clinical chart of Case 3 from birth until after recovery from pyloric stenosis.

the baby gained $3 \frac{1}{2} \mathrm{oz}$. in the following eight days. Bottle feeding alone was instituted at the age of 3 weeks but the appetite was not uniformly good and some feeds were taken slowly and remained unfinished. On the fourth day of bottle feeding, the twenty-sixth day of life, the appetite deteriorated and a phase of persistent vomiting. subnormal defaecation, and declining weight began. During the 13 days of this phase. until Rammstedt's operation was performed, the appetite remained poor, necessitating the resumption of partial gavage feeding on the third day. After five days of such feeding there was a slight improvement and gavage feeding was discontinued, but three days later partial gavage feeding was again necessary and was continued at some feeds to the time of the operation. Vomiting remained very persistent during the whole of this period, there being an average of four vomits per day and many were very copious. The bowels moved infrequently, sometimes at intervals of two or three days. The weight, which had remained stationary between the ages of $2 \frac{1}{2}$ and $3 \frac{1}{2}$ weeks and immediately before vomiting began, fell gradually during the first eight days of the vomiting phase, the loss being $6 \mathrm{oz}$., and it then remained stationary until after the operation five days later. The temperature receded to a subnormal level on the seventh day of the vomiting phase, and, except on a few occasions, remained depressed until after the operation. On the seventh day of the vomiting phase, at the age of 31 days, large waves of gastric peristalsis were observed, also 'slightly projectile vomiting, but no pyloric tumour could be felt. The tumour was felt on the following day, however, and the provisional diagnosis of pyloric stenosis thus confirmed.

Six days after making the diagnosis Rammstedt's operation was performed by J.J.M.B., after preparation with gastric lavage and saline hypodermoclyses.
Cyclopropane and local anaesthesia were used. The stomach was not grossly dilated or hypertrophied. The tumour was small and very hard. After the operation small hourly feeds of glucose water were given in increasing amounts until the second day when breast milk was resumed. The amount was gradually increased during the following days. The appetite had notably improved when feeding was resumed after the operation. and all feeds were taken well from the bottle thereafter. Slight vomiting occurred on the first two days after the operation, once on the first and twice on the second. and then ceased. The infant's general condition steadily improved and the subnormal temperature. which had been present for a week before the operation. resumed a normal level five days afterwards. The weight gained was $12 \frac{1}{2} \mathrm{Oz}$. in the first two weeks after the operation, and it continued to rise steadily. He weighed $5 \mathrm{lb}$. $10 \mathrm{oz}$. when he was discharged from hospital at the age of 11 weeks.

It was realized at the age of $5 \frac{1}{2}$ weeks that the infant's inclination to lie in the frank breech position with adduction of the right leg, which had been noticed since birth, was attributable to congenital dislocation of the hip on the right side. Orthodox treatment was begun at the age of 9 months. As infancy progressed the eyes were noticed to move in a slow, nystagmoid manner, and the pupils not to react to light, and blindness was suspected. At the age of 1 year Dr. J. R. Paterson examined the eyes under general anaesthesia and reported that: -Although the pupils remained large even in bright light, they contracted under the anaesthetic. Retinal examination showed gross congenital abnormality of both discs. These were much paler than normal, very poorly defined, and the vessels entered at their lateral sides. The child is blind and the condition not remediable. 


\section{Discussion}

Frequency of Pyloric Stenosis in Premature Infants. The scant attention given in the literature to the occurrence of pyloric stenosis in premature infants, and the tendency to consider it worthwhile to publish individual cases, suggest a lower incidence of the disease in premature than in full-term infants, but the available data on the subject do not justify such an assumption. Unfortunately, the proportion of premature infants has not been mentioned in most of the large series of cases of pyloric stenosis which have been published. In those series in which the proportion is given, the wide variation in the incidence is surprising; for instance, Levi (1941) had eight premature infants with a birth weight of $5 \frac{1}{2} \mathrm{lb}$. Or less in his series of 100 cases, whereas Svensgaard (1935) had only three 'premature' infants of unknown birth weight in her series of 224 cases. Perusal of the records of $\mathbf{4 7 0}$ infants with pyloric stenosis who were admitted to the Royal Edinburgh Hospital for Sick Children in the last $\mathbf{1 5}$ years has not enabled us to determine the proportion of premature infants in the series, since accurate birth weights were available in only a minority of cases: 26 of the series $(5 \cdot 5 \%)$ were said to have weighed $5 \frac{1}{2} \mathrm{lb}$. or less at birth, but the birth weight can be regarded as reliable in only eight cases in which birth took place in hospital. Six of the 18 infants who were born at home were said to have had a birth weight of less than $5 \mathrm{lb}$.; five of them probably weighed less than $5 \frac{1}{2} \mathrm{lb}$., since the estimated gestation period was 35 weeks or less, but the sixth was estimated to be full time. The 12 remaining infants were said to have had a birth weight of 5 to $5 \frac{1}{2} \mathrm{lb}$., and it is probable that some of this group had a birth weight exceeding the standard for prematurity of $5 \frac{1}{2} \mathrm{lb}$. Although the above evidence is not of much value in helping to determine the relative incidence of pyloric stenosis in premature and mature infants, it suggests that there is probably no significant difference. The matter can be settled only by a careful follow-up of a very large number of consecutively born infants.

Clinical Features Peculiar to Premature Infants. The published cases do not give sufficiently detailed evidence to render such an assessment possible, but analysis of the detailed records in our three cases reveals certain features which appear to be peculiar to premature infants, particularly small premature infants. These features concern the appetite, the type of vomiting, and the significance of gastric peristalsis.

APPETITE. In all three cases the appetite, which had been fairly good after the initial anorexia normally found in very premature infants, showed pronounced deterioration when the signs of pyloric stenosis developed (Figs. 1, 2, 3). This feature probably occurs in the majority of very premature infants unless the disease develops at a later stage than in our three cases; it is probably uncommon in less premature infants who usually feed well in a manner reminiscent of the voracious appetite of the mature infant with pyloric stenosis.

TYPE OF Vommrng. The vomiting in our three cases was not notably projectile. Others have observed projectile vomiting in less premature infants. It seems probable, therefore, that this unreliable but suggestive sign of pyloric stenosis is unlikely to be of much diagnostic value in small premature infants.

Significance of Gastric Peristalsis. Fairly large waves of gastric peristalsis were observed in all our cases, but often they were no larger than the waves frequently seen through the thin abdominal wall of normal small premature infants. Vickers and Conrad (1940) saw no peristalsis in their case (birth weight $4 \mathrm{lb}$. 0 oz.), and Josephs and Hendry (1950) only 'weak peristaltic waves' in an infant whose birth weight was $4 \mathrm{lb} .6 \mathrm{oz}$. We believe that exaggerated gastric peristalsis is a much less useful sign of pyloric stenosis in premature than in mature infants.

Diagnosis in Premature Infants. The diagnosis of pyloric stenosis in small premature infants is more difficult than in larger infants, because of the absence of certain classical signs. The development of anorexia associated with vomiting usually suggests an infection, but the progressive accentuation of the vomiting, the steady loss of weight, and the development of constipation constitute a picture which should always suggest the possibility of pyloric stenosis in spite of persistent anorexia.

Palpation of the hypertrophic pylorus, which is easily felt through the thin abdominal wall of premature infants, is the only sure sign of pyloric stenosis. It was palpated without much difficulty in our three cases.

Treatment in Premature Infants. There is no doubt that pyloric stenosis in premature infants, however small, should be treated surgically without delay. The prerequisites of success are the same as in all cases of pyloric stenosis, notably adequate pre-operative water and electrolyte equilibration; a skilled paediatric anaesthetist; strict isolation and good paediatric nursing. In our cases there was a dramatic improvement of the appetite after operation and convalescence was very satisfactory (Figs. 1, 2, 3).

Prompt surgical treatment is particularly important in premature infants because of the serious effects of the prolonged malnutrition inevitably associated with medical treatment, and of the lack 
of sustaining tissue reserves. Also there is a much greater risk of contracting infections, which are much more serious to premature infants, in conditions of prolonged malnutrition and hospitalization.

Aetiological Considerations. It is interesting to speculate on the possible aetiological significance of the relationship, if any, between the maturity and the age at which manifest pyloric stenosis develops. The age at which symptoms developed, in the 17 published cases in which this fact is given, did not bear any relationship to the degree of prematurity, and was no greater than the age at which the disease develops in mature infants. This fact appears to us to prove that post-natal processes, presumably increased activity of the musculature of the alimentary tract associated with the method of nourishing the organism inaugurated at birth, are responsible for the development of manifest pyloric stenosis, which rarely occurs before the age of 10 days, whatever the degree of maturity at birth. Since hypertrophy of the pyloric musculature is present in increasing degree for some time before clinical pyloric stenosis develops and has been observed at necropsy in stillborn infants, and since it may develop within two weeks of birth in very premature infants born two months before term, there would seem to be little doubt that (1) hypertrophy of the pyloric musculature is a congenital disorder, and (2) the further development of the condition to clinical pyloric stenosis is dependent on the operation of post-natal digestive processes in excess of a certain period, irrespective of the degree of maturity of the infant.

\section{REFERENCES}

Bloch, C. E. (1907). Jb. Kinderheilk., 65, 337, 477.

Dobbs, R. H. (1939). Lancet, 1, 12.

Donovan, E. J. (1932). Ann. Surg., 95, 174.

Ford, N., Brown, A. and McCreary, J. F. (1941). Amer. J. Dis. Child., 61, 41.

Gallagher, J. T. F. (1937). Ann. Surg., 106, 299.

Josephs, C. and Hendry, R. W. (1950). Brit. med. J.. 2, 681.

Laubscher, J. H. and Smith, A. M. (1947). Amer. J. Dis. Child. , 73, 334.

Levi, D. (1941). Brit. med. J., 1, 963.

Sheldon, W. (1938). Lancet, 1, 1048.

Steen, R. E. (1930). Archives of Disease in Childhood, 5,76 .

Svensgaard, E. (1935). Ibid., 10, 443.

Todd, R. McLaren (1946). M.D. Thesis, University of Oxford.

Vic (1947). Archives of Disease in Childhood, 22. 75.

Vickers, H. D. and Conrad, J. W. (1940). Amer. J. Surg., 49, 508.

Williams, H. (1942). Med. J. Aust., 1, 303. 